\title{
Influence of the prediction error of the first eye undergoing cataract surgery on the refractive outcome of the fellow eye
}

This article was published in the following Dove Press journal:

Clinical Ophthalmology

3। October 2014

Number of times this article has been viewed

\author{
Ludmilla Gorodezky ${ }^{1,2}$ \\ Babac AE Mazinani ${ }^{2}$ \\ Niklas Plange ${ }^{2}$ \\ Peter Walter ${ }^{2}$ \\ Martin Wenzel' \\ Gernot Roessler ${ }^{2}$ \\ 'Petrisberg Eye Clinic, Trier, \\ Germany; ${ }^{2}$ Department of \\ Ophthalmology, RWTH Technical \\ University of Aachen, Aachen, \\ Germany
}

Introduction: In addition to measurement errors, individual anatomical conditions could be made responsible for unexpected prediction errors in the determination of the correct intraocular lens power for cataract surgery. Obviously, such anatomical conditions might be relevant for both eyes. The purpose of this study was to evaluate whether the postoperative refractive error of the first eye has to be taken in account for the biometry of the second.

Methods: In this retrospective study, we included 670 eyes of 335 patients who underwent phacoemulsification and implantation of a foldable intraocular lens in both eyes. According to the SRK/T formula, the postoperative refractive error of each eye was determined and compared with its fellow eye.

Results: Of 670 eyes, 622 showed a postoperative refractive error within $\pm 1.0 \mathrm{D}(93 \%)$, whereas the prediction error was $0.5 \mathrm{D}$ or less in 491 eyes $(73 \%)$. The postoperative difference between both eyes was within $0.5 \mathrm{D}$ in $71 \%$ and within $1.0 \mathrm{D}$ in $93 \%$ of the eyes. Comparing the prediction error of an eye and its fellow eye, the error of the fellow eye was about half the value of the other.

Conclusion: Our results imply that substitution of half of the prediction error of the first eye into the calculation of the second eye may be useful to reduce the prediction error in the second eye. However, prospective studies should be initiated to demonstrate an improved accuracy for the second eye's intraocular lens power calculation by partial adjustment.

Keywords: cataract surgery, biometry, IOL power calculation, refractive error, fellow eye

\section{Introduction}

Since the introduction of the partial coherent laser interferometry for optical biometry, the accuracy of the intraocular lens (IOL) power calculation improved considerably. ${ }^{1-4}$ This goes along with a more accurate determination of the axial length, which was the most important reason for postoperative errors in the era of ultrasound biometry. ${ }^{5,6}$ Because of the lack of accuracy in this era, no relationship between the prediction error of the first and the fellow eye could be found. ${ }^{7}$ Although the axial length measurement lost some of its relevance as a possible error source, recent studies identified a wrong prediction of the postoperative anterior chamber depth as the most important possible error source for incorrect IOL power prediction in optical biometry. ${ }^{8,9}$

In fact, substituting the postoperatively measured anterior chamber depth (ACD) of the first eye in the calculation of the IOL power of the fellow eye has been shown to have a beneficial effect on the accuracy of the calculation. ${ }^{10}$ Recently, some investigations have been performed examining the use of empirical corrections based on the prediction error of the first eye. When the IOL power was fully adjusted in the second eye by
Department of Ophthalmology,

RWTH Technical University of Aachen,

Pauwelsstrasse 30, 52057 Aachen,

Germany

Tel +492418088227

Fax +492418082408

Email groessler@ukaachen.de 
the amount of prediction error in the first eye, no improved prediction accuracy in the second eye could be detected. ${ }^{11,12}$

However, retrospective studies have shown that correction factors of $50 \%$ derived from the prediction error of the first eye reveal a significant benefit for the accuracy of the second eye's prediction error. ${ }^{10,12,13}$

In this study, we retrospectively analyzed data on patients undergoing sequential cataract surgery on both eyes and compared the prediction error of one eye and its fellow eye to find out whether the hypothesis of an intraindividual factor, despite inaccurate biometric measurement, could be confirmed.

\section{Methods}

In our retrospective trial, we included 670 eyes of 335 consecutive patients (mean age, 75 years; range, 38-96 years) who underwent bilateral, sequential cataract surgery in the outpatient clinic in Trier. Optical biometry was performed using partial coherent laser interferometry (Zeiss IOLMaster; Carl Zeiss meditec) as part of preoperative examinations. For IOL power calculation, the SRK/T and Haigis formulas were used in all patients.

All cataract extractions were performed by one surgeon (MW) and included phacoemulsification of the crystalline lens and implantation of a foldable acrylic one-piece IOL (Acrysof SA60AT; Alcon Laboratories) into the capsular bag. The time interval between first and fellow eye surgery was at least 2 months.

Figure 1 gives information about the distribution of the refractive power of the implanted IOLs. The IOL power ranged between -2 and $33 \mathrm{D}$, with a peak of 60 implanted IOLs with a refractive power of $22.5 \mathrm{D}$.

In most cases, a target refraction of $-0.5 \mathrm{D}$ was determined for the first eye. The target refraction of the fellow eyes, which underwent surgery within a period of 2 months, was adapted according to the patients' requirements. Figure 2 shows the difference between first and fellow eye for all patients.

Two months after surgery of the second eye, clinical data, including the most recent refractions, were collected from the referring ophthalmologists. For analysis, the spherical equivalent of the best subjective correction was taken into account. The postoperative spherical equivalent was compared with the predicted refraction in all eyes. Even though in some cases the Haigis formula was used for the calculation of IOL power, the analysis accounting for anatomical conditions was exclusively performed using SRK/T.

\section{Results}

After IOL power calculation using the SRK/T formula, 622 of a total of 670 eyes (93\%) showed a postoperative spherical equivalent, which differed 1.0 D or less from the

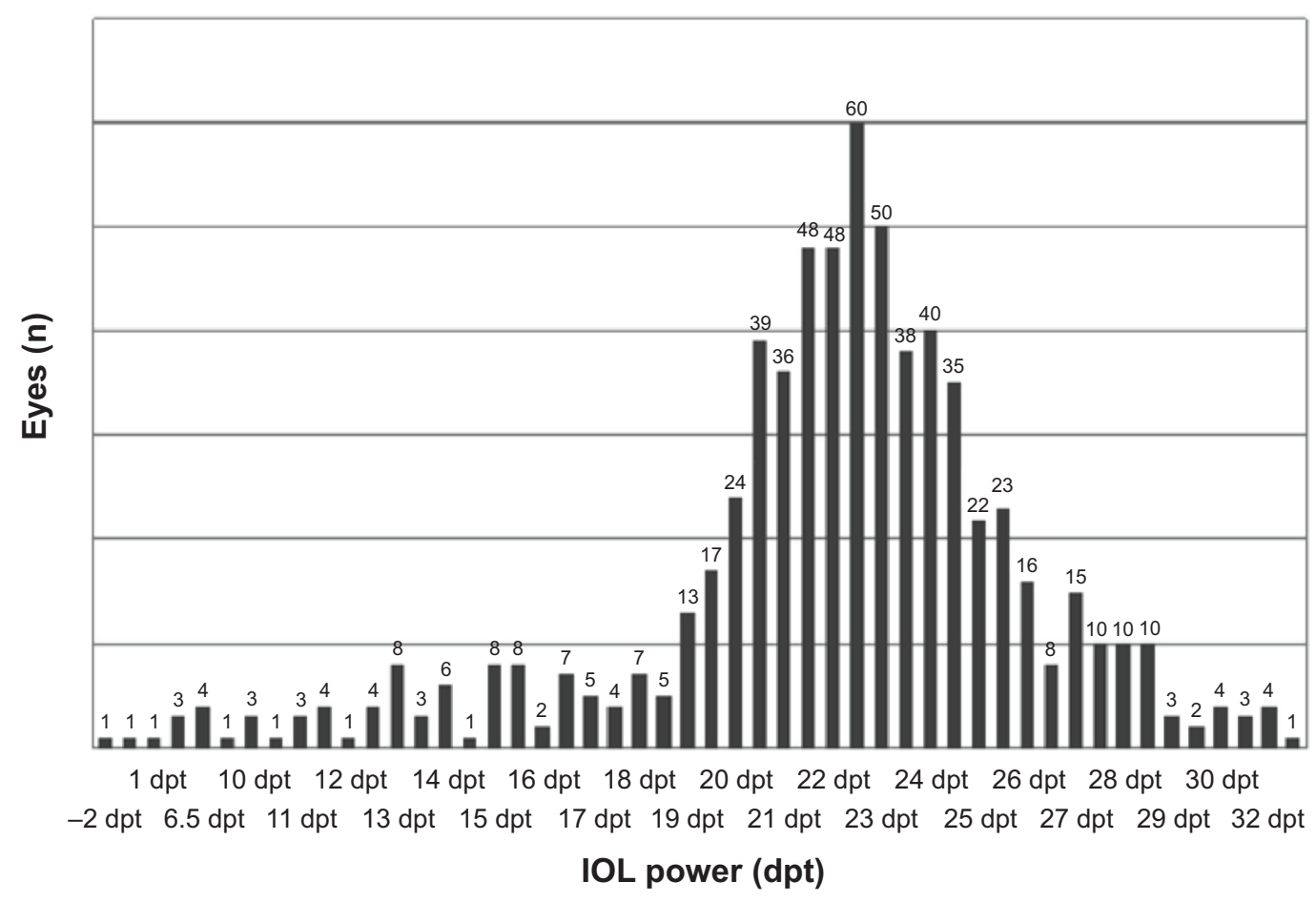

Figure I Distribution of the refractive power of the implanted intraocular lenses, with a peak of 60 eyes receiving an intraocular lens power of $22.5 \mathrm{D}$ ( $\mathrm{n}=670$ ). Abbreviations: $\mathrm{dpt}$, diopters; IOL, intraocular lens. 


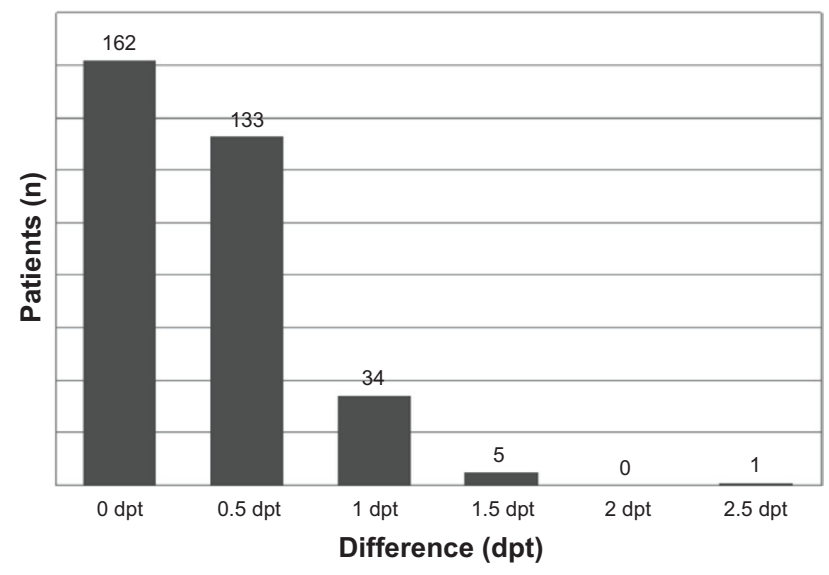

Figure 2 Difference of target refraction between the first and fellow eye for all patients (dpt, $n=335$ ).

Abbreviation: dpt, diopters.

predicted value. In 491 eyes (73\%), the prediction error was within $\pm 0.5 \mathrm{D}$; the error was more than $1.0 \mathrm{D}$ in 48 cases $(7 \%)$.

Figure 2 shows the predicted intraindividual difference in refractive outcome between first and fellow eyes in the study population of 335 subjects. In $88 \%$ of the participants, the estimated difference was within $0.5 \mathrm{D}$. To create monovision in $12 \%$ of the patients, a difference of $1.0 \mathrm{D}$ or more was aimed according to patients' requirements. In fact, the postoperative difference between both eyes was within $0.5 \mathrm{D}$ in $71 \%$ and within $1.0 \mathrm{D}$ in $93 \%$ of the patients (Figure 3).

Comparing the prediction error of both eyes, the deviation of the fellow eye was about half the value of the deviation of the first eye (Table 1). However, for eyes with a deviation of $+0.5 \mathrm{D}$, the median of the deviation of the fellow eye was $0 \mathrm{D}$, whereas the median was $-0.5 \mathrm{D}$ in fellow eyes of eyes with a prediction error of $-0.5 \mathrm{D}$. This was because all refraction values were rounded to $0.5 \mathrm{D}$ steps. For this reason, Figure 4 shows the exact distribution of the prediction

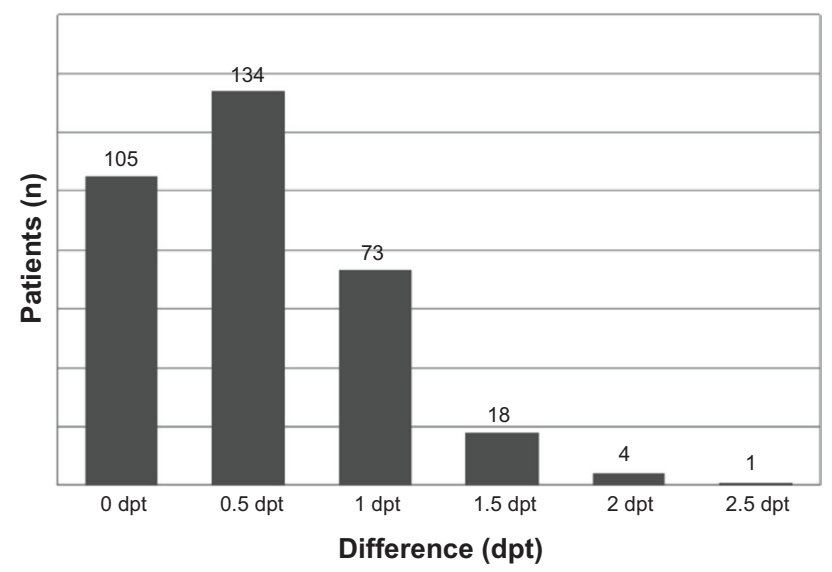

Figure 3 Postoperative difference of spherical equivalent between the first and fellow eye $(n=335)$.

Abbreviation: dpt, diopters.
Table I Prediction error of one eye compared with its fellow eye $(n=670)$

\begin{tabular}{llll}
\hline $\begin{array}{l}\text { Prediction } \\
\text { error, D }\end{array}$ & $\mathbf{N}$ & $\begin{array}{l}\text { Prediction error (D), } \\
\text { fellow eye (median) }\end{array}$ & Range (D) \\
\hline-2.0 & 6 & -1.0 & -0.5 to -1.5 \\
-1.5 & 30 & -1.0 & 0 to -2.0 \\
-1.0 & 98 & -0.5 & 0 to -2.0 \\
-0.5 & 200 & -0.5 & +1.5 to -2 \\
0 & 208 & 0 & +1.0 to -1.5 \\
+0.5 & 83 & 0 & +1.5 to -0.5 \\
+1.0 & 33 & +0.5 & +2.0 to -0.5 \\
+1.5 & 9 & +1.0 & +3.0 to -0.5 \\
+2.0 & 2 & +1.0 & - \\
\hline
\end{tabular}

Note: The deviation of the fellow eye was about half the value of the deviation of the first eye.

error values. For example, at a prediction error of $+0.5 \mathrm{D}$ for the first eye, the majority of deviation values for the fellow eye could be found at 0.0 and $+0.5 \mathrm{D}$, whereas at $-0.5 \mathrm{D}$, most of the values of the second eye were at -0.5 and $0.0 \mathrm{D}$, respectively (Figure 4).

In addition, in all patients, the postoperative refraction error showed the same prefix in both eyes. For example, if one eye shows a myopic shift, the fellow eye never revealed a hyperopic deviation, and vice versa.

\section{Discussion}

$\mathrm{SRK} / \mathrm{T}$, as well as the Haigis formula, is commonly used for IOL power calculation before cataract surgery. ${ }^{14-16}$ Although both formulas have been confirmed to deliver satisfying results in regard to the postoperative refractive error in the majority of eyes, the Haigis formula seems to deliver better results in eyes with extreme myopia and hyperopia. ${ }^{17-20}$ Even though we used both formulas for preoperative IOL power calculation, for our analysis of data of the IOL power calculation, the SRK/T formula was exclusively taken into account. This was determined by the aim of our study, which was not to evaluate the accuracy of the IOL power calculation by using a special formula but to analyze in which way the prediction error of the first eye is relevant for the postoperative refraction of the fellow eye.

The replacement of the crystalline lens with a thinner IOL reveals certain variability with regard to the exact postoperative position of the IOL within the capsular bag and the postoperative anterior chamber depth. This means that in addition to measurement errors, individual anatomical conditions could be made responsible for unexpected prediction errors. Obviously, such anatomic conditions might be relevant for both eyes. 
Refractive error (dpt)

\begin{tabular}{|c|c|c|c|c|c|c|c|c|c|c|c|c|}
\hline & -2.0 & -1.5 & -1.0 & -0.5 & 0.0 & +0.5 & +1.0 & +1.5 & +2.0 & +2.5 & +3.0 & $\Sigma$ \\
\hline-3.0 & & & & & & & & & & & & \\
\hline-2.5 & & & & & & & & & & & & 0 \\
\hline-2.0 & & 2 & 2 & 2 & & & & & & & & 6 \\
\hline-1.5 & 2 & 8 & 14 & 5 & 1 & & & & & & & 30 \\
\hline-1.0 & 2 & 14 & 32 & 38 & 12 & & & & & & & 98 \\
\hline-0.5 & 2 & 5 & 38 & 78 & 56 & 19 & 1 & 1 & & & & 200 \\
\hline 0.0 & & 1 & 12 & 56 & 102 & 28 & 9 & & & & & 208 \\
\hline+0.5 & & & & 19 & 28 & 20 & 13 & 3 & & & & 83 \\
\hline+1.0 & & & & 1 & 9 & 13 & 6 & 2 & 2 & & & 33 \\
\hline+1.5 & & & & 1 & & 3 & 2 & 2 & & & 1 & 9 \\
\hline+2.0 & & & & & & & 2 & & & & & 2 \\
\hline+2.5 & & & & & & & & & & & & 0 \\
\hline+3.0 & & & & & & & & 1 & & & & 1 \\
\hline$\Sigma$ & 6 & 30 & 98 & 200 & 208 & 83 & 33 & 9 & 2 & 0 & 1 & 670 \\
\hline
\end{tabular}

Figure 4 Refractive error of one eye in comparison with its fellow eye.

Notes: Number of patients with their intraindividual deviation; higher deviations are marked by darker background colors. Abbreviation: dpt, diopters.

The surgeon who realizes a certain prediction error for the first eye would appreciate a method for taking this information into account in the calculation for the fellow eye waiting for cataract extraction, especially if this error was $1 \mathrm{D}$ or more. Olsen reported on favorable results when the measured postoperative ACD of the first eye was included as the estimated ACD into the IOL power calculation of the fellow eye. ${ }^{10}$ In the same study, similar results were achieved when using different correction coefficients for commonly used formulas. In the case of using the SRK/T formula, for example, a refractive error of $1.0 \mathrm{D}$ would call for $0.57 \mathrm{D}$ for IOL power correction to obtain the target refraction of the second eye. ${ }^{10}$ These results may explain why the adjustment in the second eye by the full prediction error of the first eye did not show any improvement of the fellow eye's prediction accuracy. ${ }^{11}$ In contrast, the results go along with our investigations, in which the second eyes, on average, show half the amount of prediction error compared with the first eye when the SRK/T formula was used for IOL power calculation. Moreover, in recent studies, prediction error values were back-calculated to find out in which way a partial adjustment according to the first eye's error may improve the refractive outcome. Both authors found that the partial adjustment by $50 \%$ would deliver the best prediction accuracy in the second eye. ${ }^{12,13}$

In conclusion, we agree with the authors that substitution of half of the prediction error of the first eye into the calculation of the second eye could be useful. However, this recommendation is based on retrospective calculations, which reveal certain problems. For example, as IOLs are manufactured in steps of $0.5 \mathrm{D}$, in cases of a prediction error that is not divisible by 0.5 , the surgeon again is spoilt for choice. This could reduce the beneficial effect of partially adjusting for the first eye under prospective conditions. ${ }^{12}$ Nevertheless, prospective studies should be initiated to demonstrate an improved accuracy for the second eye's IOL power calculation by a partial adjustment in the daily routine.

\section{Disclosure}

The authors report no conflicts of interest in this work.

\section{References}

1. Haigis W, Lege B, Miller N, Schneider B. Comparison of immersion ultrasound biometry and partial coherence interferometry for intraocular lens calculation according to Haigis. Graefes Arch Clin Exp Ophthalmol. 2000;238(9):765-773.

2. Findl O, Drexler W, Menapace R, Heinzl H, Hitzenberger CK, Fercher AF. Improved prediction of intraocular lens power using partial coherence interferometry. J Cataract Refract Surg. 2001;27(6): 861-867.

3. Rajan MS, Keilhorn I, Bell JA. Partial coherence laser interferometry vs conventional ultrasound biometry in intraocular lens power calculations. Eye (Lond). 2002;16(5):552-556.

4. Packer M, Fine IH, Hoffman RS, Coffman PG, Brown LK. Immersion A-scan compared with partial coherence interferometry: outcomes analysis. J Cataract Refract Surg. 2002;28(2):239-242.

5. Kora Y, Koike M, Suzuki Y, Inatomi M, Fukado Y, Ozawa T. Errors in IOL power calculations for axial high myopia. Ophthalmic Surg. 1991;22(2):78-81.

6. Olsen T. Sources of error in intraocular lens power calculation. J Cataract Refract Surg. 1992;18(2):125-129.

7. Olsen T, Løgstrup N, Olesen H, Corydon L. Using the surgical result in the first eye to calculate intraocular lens power for the second eye. J Cataract Refract Surg. 1993;19(1):36-39.

8. Olsen T. Improved accuracy of intraocular lens power calculation with the Zeiss IOLMaster. Acta Ophthalmol Scand. 2007;85(1):84-87.

9. Norrby S. Sources of error in intraocular lens power calculation. J Cataract Refract Surg. 2008;34(3):368-376.

10. Olsen T. Use of fellow eye data in the calculation of intraocular lens power for the second eye. Ophthalmology. 2011;118(9):1710-1715. 
11. Jabbour J, Irwig L, Macaskill P, Hennessy MP. Intraocular lens power in bilateral cataract surgery: whether adjusting for error of predicted refraction in the first eye improves prediction in the second eye. J Cataract Refract Surg. 2006;32(12):2091-2097.

12. Covert DJ, Henry CR, Koenig SB. Intraocular lens power selection in the second eye of patients undergoing bilateral, sequential cataract extraction. Ophthalmology. 2010;117(1):49-54.

13. Aristodemou P, Knox Cartwright NE, Sparrow JM, Johnston RL. First eye prediction error improves second eye refractive outcome results in 2,129 patients after bilateral sequential cataract surgery. Ophthalmology. 2011;118(9):1701-1709.

14. Narváez J, Zimmerman G, Stulting RD, Chang DH. Accuracy of intraocular lens power prediction using the Hoffer Q, Holladay 1, Holladay 2, and SRK/T formulas. J Cataract Refract Surg. 2006;32(12): 2050-2053.

15. Aristodemou P, Knox Cartwright NE, Sparrow JM, Johnston RL. Formula choice: Hoffer Q, Holladay 1, or SRK/T and refractive outcomes in 8,108 eyes after cataract surgery with biometry by partial coherence interferometry. J Cataract Refract Surg. 2011;37(1):63-71.
16. Tehrani M, Krummenauer F, Blom E, Dick HB. Evaluation of the practicality of optical biometry and applanation ultrasound in 253 eyes. J Cataract Refract Surg. 2003;29(4):741-746.

17. Roessler GF, Dietlein TS, Plange N, et al. Accuracy of intraocular lens power calculation using partial coherence interferometry in patient with high myopia. Ophthalmic Physiol Opt. 2012;32(3):228-233.

18. Bang S, Edell E, Yu Q, Pratzer K, Stark W. Accuracy of intraocular lens calculations using the IOLMaster in eyes with long axial length and a comparison of various formulas. Ophthalmology. 2011;118(3): 503-506.

19. Roh YR, Lee SM, Han YK, Kim MK, Wee WR, Lee JH. Intraocular lens power calculation using IOLMaster and various formulas in short eyes. Korean J Ophthalmol. 2011;25(3):151-155.

20. Terzi E, Wang L, Kohnen T. Accuracy of modern intraocular lens power calculation formulas in refractive lens exchange for high myopia and high hyperopia. J Cataract Refract Surg. 2009;35(7):1181-1189.
Clinical Ophthalmology

\section{Publish your work in this journal}

Clinical Ophthalmology is an international, peer-reviewed journa covering all subspecialties within ophthalmology. Key topics include: Optometry; Visual science; Pharmacology and drug therapy in eye diseases; Basic Sciences; Primary and Secondary eye care; Patien Safety and Quality of Care Improvements. This journal is indexed on

Submit your manuscript here: http://www.dovepress.com/clinical-ophthalmology-journal

\section{Dovepress}

PubMed Central and CAS, and is the official journal of The Society of Clinical Ophthalmology (SCO). The manuscript management system is completely online and includes a very quick and fair peer-review system, which is all easy to use. Visit http://www.dovepress.com/ testimonials.php to read real quotes from published authors. 